\title{
La(s) vida(s) de Ernesto, el "Che" Guevara: cuatro miradas biográficas y una novela*
}

\author{
Gilda Waldman M.**
}

\section{Resumen}

La escritura biográfica, como género, alberga en su interior una gran diversidad de métodos, enfoques, miradas y modelos que comparten un rasgo central: se trata de textos interpretativos, pues ningún pasado individual se puede reconstruir fielmente. En este sentido, cabe referirse a algunas de las más importantes biografías existentes sobre el Che Guevara, como La vida en rojo, de Jorge G. Castañeda, (Alfaguara 1997); Che Ernesto Guevara. Una leyenda de nuestro siglo, de Pierre Kalfon (Plaza y Janés, 1997); Che Guevara. Una vida revolucionaria, de John Lee Anderson (Anagrama, 2006) y Ernesto Guevara, también conocido como el Che, de Paco Ignacio Taibo II (Planeta, 1996). Por otro lado, en la vida del Che, hay silencios oscuros que las biografías no cubren, salvo de manera muy superficial. Algunos de estos vacíos son retomados por la literatura, por ejemplo, a través de la novela de Abel Posse, Los Cuadernos de Praga.

Palabras clave: Che Guevara, biografías, interpretación, literatura.

\section{Ernesto "Che" Guevara's Lives. Four Biographies and one Novel}

\begin{abstract}
The biographical writing, as a genre, shelters inside a wide diversity of methods, approaches, points of view and models that share a central trait: it is an interpretative text, since no individual past can be faithfully reconstructed. In this sense, it is worth referring to some of the most diverse and important biographies written about Che Guervara, (Jorge G. Castañeda: La vida en rojo, Alfaguara 1997; Pierre Kalfon: Che Ernesto Guevara. Una leyenda de nuestro siglo, Plaza y Janés, 1997; John Lee Anderson: Che Guevara. Una vida revolucionaria, Anagrama, 2006, and Paco Ignacio Taibo II: Ernesto Guevara, también conocido como el Che, Planeta, 1996, On the other hand, there are dark silences that these biographies do not cover, except superficially. This vacuum is seized by literature, for example, in the form of Abel Posse's novel, Los Cuadernos de Praga.
\end{abstract}

Keywords: Che Guevara, biographies, interpretation, literature.

\footnotetext{
*Artículo ampliado a partir de la ponencia presentada en las Jornadas "Vidas Ajenas: perfiles, retratos y biografías latinoamericanos", realizadas en Santiago de Chile el 24 y 25 de mayo del año 2016.

** Chilena, Doctora en Sociología por la Universidad Nacional de México. Académica Facultad de Ciencias Políticas y Sociales, Universidad Nacional de México, D.F, México.gwaldman18@gmail.com
} 
"La verdad biográfica no se puede poseer, y aunque uno la posea, no puede usarla".

Carta de Freud a Stefan Zweig

"La historia de una vida nunca se recopila, siempre se inventa. La inventa el que la cuenta y la reinventa el que la escucha; ambos interpretan".

Mario Vargas Llosa

"Los científicos dicen que estamos hechos de átomos pero a mí un pajarito me contó que estamos hechos de historias".

Eduardo Galeano

¿Cómo escribir la vida de otro? ¿Cómo desafiar al fantasma de Alberto Caeiro -uno de los heterónimos de Fernando Pessoa- y su aseveración que señala: "si, después de morir, quisieran escribir mi biografía, nada más sencillo. Hay sólo dos fechas: la de mi nacimiento y la de mi muerte. Entre una y otra cosa, son todos los días míos? (1984: 145). ¿Cómo "atrapar" el flujo complejo de la vida biografiada sólo con palabras y en una cantidad definida de páginas como si ésta pudiera haber sido lineal y coherente, y no discontinua y plural, formada por vivencias yuxtapuestas y aleatorias?

La escritura biográfica es paradójica. Procura recrear una vida pero ninguna existencia se puede reproducir en su totalidad, ni siquiera con la más detallada cronología ni con el más exhaustivo catálogo de acciones, pues la vida contada no es la vivida y ningún relato puede reconstruir su trayectoria tal como exactamente fuera experimentada. Ceñida a datos reales, siempre constituirá un texto interpretativo de un itinerario vital recorrido por grietas, intersticios y fracturas. Sustentada en una multiplicidad de fuentes, sabe que "ninguna (fuente) es perfecta o suficiente en sí misma, (y que) incluso las más irreprochables en apariencia -cartas, notas o diarios del sujeto de la misma biografía- entrañan contradicciones y reservas: ¿quién es transparente consigo mismo?" (Castañeda, La vida en rojo 17). Impulsada por el afán de poner orden en el caos de lo vivencial para darle significación a la trayectoria de una vida, deberá jerarquizar los momentos clave de la biografía del biografiado. Alentada por el afán de conocimiento, no podrá ser ajena a estrategias literarias (voces narrativas, tensiones dramáticas, manejo del tiempo, desenlace, etc.) y deberá conjugar el rigor de los datos confirmables con la pasión por la narración, asumiendo que toda escritura biográfica es un acto de amor. Nutrida por la voluntad de rigor histórico, la escritura biográfica debe meterse en la 
piel del biografiado y recurrir a la empatía para descifrar las emociones, sentimientos, motivaciones y acciones de éste, pero también a la imaginación para llenar los vacíos que se pueda encontrar a lo largo de su vida. ${ }^{1}$

Si toda investigación es una aventura, escribir una biografía es una especie de salto al vacío. No sólo se trata de construir un relato que seduzca al lector presentando las complejidades de una personalidad que amerite ser biografiado, sino que implica también una mezcla de géneros: historia, sociología, periodismo, psicoanálisis. El punto de partida del biógrafo es una mesa de trabajo con materiales dispersos: notas, fichas, mapas, revistas, fotografías, libros, cartas, memorias, testimonios personales, recuerdos, confesiones, semblanzas íntimas, diarios, crónicas, genealogías, etc. ¿Cómo no perderse en la memoria de la figura biografiada? ¿Cómo introducir coherencia en un material caótico y huidizo? Quien escribe una biografía es, ante todo, un lector paciente que, por una parte, entabla con el personaje biografiado una relación intensa y pasional, lo cual imposibilita cualquier presunción de conocimiento objetivo, y por la otra, debe guardar cierta distancia para que su texto no se convierta en una narración reverencial. De todos modos, el misterio de una vida siempre se le (nos) escapará. La narración del Otro será un caleidoscopio que, por más testimonial y veraz que se pretenda, obedecerá a un trabajo de interpretación y, por qué no, también en muchos casos, de ficcionalización. La escritura de la vida de Otro solo puede ser entonces una versión tentativa, aproximada, provisional, libre y especulativa. Es decir, una conjetura. ¿Y cómo no conjeturar cuando se trata de escribir la biografía de un personaje tan complejo y contradictorio como Ernesto, el Che Guevara, y se desea ir más allá del héroe que parece presentársenos sin fisuras, impermeable a la duda? Ciertamente, no es una tarea fácil reconstruir la biografía de un hombre con una pasión compulsiva por escribir, que dejó cartas personales y públicas, notas manuscritas, artículos, libros, discursos, conferencias, entrevistas, poemas, comentarios de autores leídos y, ciertamente, su propia autobiografía a través de diarios en los que narraba lo que vivía. (Sabemos que quien aparece en cualquier autobiografía no es un rostro real, sino una máscara discursiva). ¿Cómo escribir sobre un personaje que vivió "rodeado de narradores, testimo-

1 Hago referencia a aquellas biografías rigurosas y documentadas en una gran diversidad de fuentes, escritas por historiadores o biógrafos profesionales, quienes emprenden su tarea por un interés genuino, a veces casi obsesivo, por el personaje biografiado, y no a aquellas que responden a intereses de otro orden, sea mercantil o sensacionalista. 
niantes, voces amigas que cuentan y lo cuentan" (Taibo, Ernesto Guevara 732) si también nos resulta claro que "no todo lo que dicen o escriben los protagonistas es cierto" (Castañeda, La vida en rojo 19)?

$\mathrm{Si}$, como escribía Borges, en cada hombre hay por lo menos dos o tres hombres, no podemos dejar de reconocer que es una labor monumental escribir la biografía de una figura tan controvertida, de innumerables rostros, de personalidad multifacética; una figura épica que desarrolló una teoría de la revolución latinoamericana y que anhelaba unificar a América Latina mediante la revolución armada pero que fue, durante largo tiempo, fiel a la ortodoxia stalinista; un hombre que fue artífice de la concepción del "hombre nuevo", ejemplo de una nueva cultura, una nueva sensibilidad y nuevas alternativas de vida pero que, al mismo tiempo, fue el responsable de decenas de ejecuciones después del triunfo de la revolución cubana; un personaje que simbolizó la búsqueda de la revolución a escala mundial para la izquierda latinoamericana y los intelectuales europeos y, simultáneamente, un individuo implacable y soberbio, un estratega fallido que fracasó dos veces: en las trágicas aventuras guerrilleras en el Congo $(1965)^{2}$ y en Bolivia $(1967)^{3}$ y cuyas políticas económicas en Cuba fueron ineficaces al poco tiempo de implementadas. ${ }^{4}$

2 El Che Guevara, junto con una pequeña expedición de soldados cubanos, desembarcó en abril de 1965 en la zona oriental del Congo para unirse a las fuerzas rebeldes de Laurent-Désiré Kabila, en su lucha contra las autoridades y el ejército congoleño, las tropas norteamericanas y un ejército mercenario sudafricano, en el marco de las varias insurrecciones armadas generadas después del asesinato de Patricio Lumumba, primer Presidente después de la descolonización, y hombre cercano a la Unión Soviética. La implicación de Estados Unidos en el asesinato de Lumumba y en la lucha anti-rebelde llevó a que la Unión Soviética, Cuba y China se involucraran apoyando a los movimientos rebeldes. El objetivo del Che era contribuir a la lucha guerrillera e instalar una plataforma revolucionaria en África. Sin embargo, la falta de contacto con Kabila, la reticencia de los congoleños a combatir, la falta de coordinación entre los soldados nativos y los cubanos, la incomprensión del Che en torno a la realidad cultural y tribal africana, las enfermedades tropicales (que llevaron a una alta deserción de soldados cubanos), la precariedad de la situación militar, etc., se tradujeron en un catastrófico fracaso. Guevara abandonó el Congo en noviembre de 1965.

3 El Che Guevara llegó a Bolivia en noviembre de 1966 a crear un foco guerrillero del cual se irradiarían, posteriormente, movimientos armados en otros países latinoamericanos, uno de los cuales sería Argentina, su país de origen. Sin embargo, la mala planeación inicial (que escogió al azar una zona montañosa y selvática lejos de centros urbanos para instalar a la guerrilla, sin un buen conocimiento previo del terreno), la falta de apoyo del Partido Comunista Boliviano (y en general, de todo apoyo político en Bolivia) así como la indiferencia (e incluso la delación) del campesinado (que a raíz de la Reforma Agraria de 1953 era propietario de sus tierras), la dificultad para que llegaran aprovisionamientos y medicinas, la desconexión de la guerrilla con su red urbana de apoyo, una mala evaluación de los acontecimientos, la situación de "extranjería" del Che en Bolivia, una cierta incompetencia logística (como dejar fotografías y documentos personales en campamentos a los que llegaba el ejército en su afán de desbaratar la guerrilla), la falta de comunicación y, según ciertos autores (Castañeda, La vida en rojo), el abandono por parte de Fidel Castro, se tradujeron en el fracaso del Che Guevara en Bolivia y en su muerte en octubre de 1967 en el pequeño poblado de La Higuera.

4 Después de la Revolución, el Che Guevara ocupó los cargos de Director del Banco Nacional de Cuba, Director del Departamento de Industria del Instituto Nacional de la Reforma Agraria y, más tarde, el de Ministro de Industria. Su proyecto de industrialización se enfrentó a numerosos obstáculos: falta de mano de obra preparada, incapacidad del país para construir maquinaria, carencia de materias 
No es sencillo escribir la biografía de un personaje que se resignifica permanentemente: ícono revolucionario del idealismo y la rebeldía juvenil y la cara más visible de la lucha antiimperialista durante la década de los sesenta, metáfora de la tragedia de los desaparecidos a partir de la incógnita sobre sus restos, modelo para los jóvenes en contra de la guerra de Vietnam, para los negros sudafricanos, para el zapatismo mexicano, los estudiantes chilenos, la insurgencia colombiana, los indígenas bolivianos y los piqueteros argentinos. ¿Cómo escribir sobre quien fuera modelo de congruencia ética y política y, al mismo tiempo, al menos para las nuevas generaciones, una simple figura en camisetas, ceniceros, gorras de béisbol, encendendores, llaveros, jeans, cervezas e, incluso, el protagonista de una novela gráfica? ¿Cómo explicar la fascinación que experimentan los jóvenes de distintos continentes y condiciones sociales hacia Ernesto Guevara, jóvenes que ni siquiera habían nacido cuando el Che murió y que poco saben sobre la revolución mundial que él quería? ${ }^{5}$ ¿Cómo desentrañar quien fue el personaje real tras el mito y la pose fotográfica?

El Che sigue estando presente, sin duda, en nuestra contemporaneidad, inspirando la imaginación de tres generaciones, no sólo por la expansión comercial de que lo vuelve una figura omnipresente, sino porque, convertido a la vez en una figura simbólica y mítica, persiste en el imaginario y la memoria colectiva, particularmente de América Latina. Como figura simbólica, representa una imagen seminal de la prodigiosa década de los sesenta, misma que ha dejado una huella imborrable en las décadas posteriores. Clave en la historia cultural del siglo XX, los años sesenta vieron aflorar la contracultura, los estilos de vida alternativos, la insurgencia juvenil cargada de una impronta de rebeldía, la dignificación de la diversidad cultural, los movimientos antiautoritarios, la búsqueda íntima de una nueva ética y, ciertamente, las desmesuradas batallas utópicas en pro de "otro mundo posible". El Che fue, en este sentido, la encarnación de una épica, la representación del sueño de toda una generación que vivió el torbellino de una atmósfera cultural y emocional fuertemente ideologizada, en la que las calles fueron, para ella, el espacio de encuentro para intentar iniciar un cambio radical en pro de mayor justicia e igualdad. Y, ciertamente, en una época como la nuestra, en la que quizá

primas (carbón, hierro, etc.), tardanza de los países socialistas para entregar las fábricas prometidas, carencia de divisas, etc. La política de industrialización fue, así, un fracaso, y Cuba tuvo que depender del monocultivo y la exportación de azúcar.

5 En Cuba, la figura del Che sigue siendo profundamente reverenciada. Su figura en fotos, monumentos y afiches se encuentra en calles y avenidas de todo el país. 
nunca como ahora el presente había estado tan marcado por la voluntad social de recordar, la década de los sesenta permanece nostálgicamente en nuestro imaginario a través de la memoria musical, la moda vintage, la proliferación de exposiciones históricas y fotográficas, o la producción de series televisivas en el marco de lo que Andreas Huyssen (2002) ha llamado "una obsesión memorialista", como respuesta al "deseo de anclarnos en un mundo caracterizado por una creciente inestabilidad del tiempo y por la fracturación del espacio en el que vivimos" (24). En esta línea, la nostalgia alcanza, sin duda, a la figura del Che, el héroe carismático que encarna míticamente -es decir, más allá de la historia y la prosaica realidad- el idealismo, la rebeldía, el coraje, el desinterés, el desapego, la independencia, la integridad, la valentía, la voluntad de acero, etc., de un justiciero revolucionario, en un entorno de descreimiento político, caída de proyectos utópicos y desapasionamientos ideológicos.

Desconocemos todavía cómo se conmemorarán en 2017 los cincuenta años de la muerte del Ché Guevara en Bolivia. Pero veinte años atrás, en 1997, en el trigésimo aniversario de su asesinato, proliferaron películas y documentales, reportajes televisivos e innumerables artículos de prensa y suplementos especiales. Discos, recitales artísticos y exposiciones fueron también parte de la oleada memorialista en torno al Ché. Sus restos -o lo que se supone son sus restos- (Rico y De La Grange 2008) y las de una parte de los compañeros muertos junto a él en Bolivia eran llevados a Cuba -en el marco del "período especial" ${ }^{6}$ y también de la proclamación de 1997 como "Año del Che" -y depositados en un memorial construido ex profeso en la ciudad de Santa Clara. Ello no era casual. En el marco del entonces reciente desmoronamiento del bloque socialista, y debilitadas las ideas y causas movilizadoras del socialismo, la figura del Che, jugándose su vida al todo o nada, se enaltecía. El mercado editorial tampoco fue ajeno a su gloria mediática. En 1997 aparecían publicadas tres importantes biografías de su figura. La vida en rojo, de Jorge G. Castañeda (México, Alfaguara, 1997); Che Guevara. Una vida revolucionaria, de Jon Lee Anderson (Barcelona, Emecé, 1997); Che Ernesto Guevara. Una leyenda de nuestro siglo, de Pierre Kalfon (Lugar, Plaza y Janés, 1997). Un año antes, en 1996, había aparecido Ernesto Guevara, también conocido como

6 El "período especial" fue la etapa de crisis que sobrevino en Cuba después del colapso de la Unión Soviética y del fin de la ayuda económica que este país proporcionaba a la isla (petróleo, maquinaria, inversiones, etc.). Ello se tradujo en medidas de austeridad, escasez de alimentos y de combustible, falta de medios de transporte, apagones eléctricos fábricas, semi-paralizadas, etc. 
el Che, de Paco Ignacio Taibo II (Lugar, Planeta, 1996). ${ }^{7}$ A todas ellas se agregaban a algunas otras, escritas poco tiempo después de su muerte, y que respondían más bien a razones políticas en el contexto de la Guerra Fría, y a las cuales se han añadido, en fechas recientes, algunas otras. ${ }^{8}$

Las cuatro biografías a las que hacemos referencia están nutridas de un caudal de materiales diversos -gran parte de ellos inéditos hasta entonces- que comparten muchas de las mismas fuentes, principalmente bibliográficas y hemerográficas, así como testimonios y entrevistas con (casi) los mismos informantes, personas que trataron al Che en los momentos decisivos de su vida en Argentina, Guatemala, México, Cuba, el Congo y Bolivia. Pero, ciertamente, no existe una lectura neutral. Información similar, proveniente de las mismas fuentes, será leída de manera distinta y relativa, mediada y matizada por la subjetividad, las propias líneas de pensamiento, la experiencia, y la historia personal, política y generacional de cada uno de sus biógrafos. Como afirma Paco Ignacio Taibo II (1996): "Nadie es propietario de documentos, tan solo de interpretaciones" (10). A las fuentes compartidas, cada uno de los biógrafos mencionados agregó muchas otras, producto de sus propias investigaciones. Por ejemplo, Jon Lee Anderson, periodista, cronista de guerra, especialista en temas latinoamericanos, cercano a la revolución cubana, se sustentó principalmente en material hasta entonces no conocido, guardado en los herméticos archivos cubanos. Además, fue el único que contó con el apoyo de la viuda del Che, quien le permitió la lectura de sus diarios inéditos, el Diario de un combatiente, escrito por Guevara en la Sierra Maestra y publicado parcialmente, pero inédito en su totalidad. (724). Anderson, además entrevistó a militares bolivianos que estuvieron en La Higuera, el pequeño poblado en el que fuera asesinado Guevara, durante los últimos días de vida del guerrillero. A su vez, Paco Ignacio Taibo II, un prolífico narrador de novelas policiacas, un hombre polémico e ideológicamente comprometido con la izquierda mexicana, para escribir su biografía sobre el Che se apoyó en un cúmu-

7 En el 2017 apareció una versión actualizada de esta biografía. Dado que este texto se entregó en enero del mismo año, no pudo ser consultada.

8 Entre las cuales se pueden citar las siguientes: Pacho O'Donnell: Che. la vida por un mundo mejor. México, Plaza y Janés, 2003.Ciro Bustos: El Che quiere verte: la historia jamás contada del Che en Bolivia. Buenos Aires, J. Vergara, 2007; Gabriel Glasman, Breve historia del Che Guevara. Madrid, Nowtilus, 2008; Alberto Muller: Che Guevara. Valgo más vivo que muerto. Biblioteca Nueva, 2014. En el 2017, Paco Ignacio Taibo II publicó una versión actualizada, con información inédita sobre la vida de Ernesto Guevara, ampliando su biografía previa. Véase Ernesto Guevara, también conocido como el Che, México, Planeta, 2017. 
lo descomunal de recursos documentales e información periodística dispersa en periódicos cubanos, argentinos, españoles y mexicanos. Jorge Castañeda (1995), a su vez, actualmente un polémico intelectual que ha revisado críticamente la historia política y social de la izquierda latinoamericana, y quien durante su juventud fuera muy cercano a la revolución cubana, para luego desencantarse de ella, indagó en "los archivos de Estado de los países involucrados, directa o indirectamente, en la vida y muerte del Che" (17) y, particularmente, en los archivos "desclasificados" de los servicios de inteligencia estadounidenses, exsoviéticos e ingleses, además de entrevistarse con muchos agentes que formaron parte de los mismos, y de recuperar numerosos testimonios de personas cercanas a Guevara. Por su parte, Pierre Kalfon (1997) -periodista, escritor y diplomático francés- se nutrió de una amplia bibliografía, diarios, periódicos, filmografía y numerosas entrevistas.

Cuatro biografías, cuatro diferentes formas posibles de escribir la vida de Ernesto Guevara, el Che, pese a que todas siguen la cronología lineal: el niño enfermo de asma crónica, el joven de voluntad indomable, el joven médico que viaja por América, el combatiente de la Sierra Maestra, el Ministro de Economía y Presidente del Banco Central en la Cuba posrevolucionaria, y el guerrillero que abandona Cuba para iniciar nuevas guerras revolucionarias en el Congo y Bolivia. Todas estas imágenes sujetas a los datos provenientes de las fuentes ya mencionadas y renuentes a la ficcionalización. Cuatro relatos diferentes: las de Anderson y Taibo II, predominantemente narrativas; las de Castañeda y Kalfon, mucho más interpretativas. Mientras que la de Jon Lee Anderson, se construye a partir de dos preguntas iniciales:

¿Quién era ese hombre que a los treinta y seis años había abandonado a su esposa y cinco hijos, su puesto de ministro y grado de comandante en la Cuba revolucionaria con la esperanza de iniciar una revolución continental? ¿Qué había impulsado a este hijo de una familia aristocrática argentina, con título de médico, a tratar de cambiar el mundo? (Anderson 11-12)

Sigue de manera puntual, meticulosa y detallada, con la pluma ágil del cronista y en un formato cercano al reportaje periodístico, con una mirada admirativa que ofrece una imagen positiva del personaje aunque sin excluir totalmente algunos de los claroscuros de su vida y su trayectoria vital -como su papel en las ejecuciones de funcionarios del derrocado General Fulgencio Batista durante los primeros días de la revolución-, 
buscando en su escritura biográfica la mayor exactitud y veracidad.

Taibo II (1996), a su vez -para quien la historia debe dejar de lado la dimensión críptica del lenguaje académico sin perder el rigor de los datos-, construye una narración más compleja al entretejer su propia y fluida narración con la propia voz del Ché a partir de sus escritos, convirtiéndola a ésta en segunda voz narrativa. Al relatar uno de los episodios guerrilleros en la Sierra Maestra, escribe, por ejemplo: "La guerrilla se pone nuevamente en movimiento". Y agrega, a continuación, pero ahora en voz del Ché: "En aquellos momentos caminábamos sin rumbo fijo y a marcha lenta, escondidos en pequeños cayos del monte" (163). En cambio, las biografías de Castañeda (1997) y Kalfon (1997) tienen un registro escritural distinto. La primera, La vida en rojo, se halla más cercana a un formato académico (con notas a pie de página y notas al final del texto) y, de manera provocadora, está orientada a comprender a Guevara desde el análisis sicológico y del entorno político, enmarcando su trayectoria vital, por una parte, como una "fuit en avant" (Castañeda 23) ¿a la distancia, al viaje, a la muerte? para escapar a toda ambivalencia, desencadenante de una angustia traducida en atroces ataques de asma a lo largo de su vida. Por la otra, como un conflicto irresoluble entre el permanente idealismo de sus creencias y la realpolitik-con su juego de fríos intereses políticos-, lo cual le resultará devastador. La fotografía del Che muerto, tomada por el ejército boliviano horas después de su asesinato, y que lo asemeja a Cristo, le permite a Castañeda explicar la formación del mito en torno al Ché:

El ejército boliviano transformó al revolucionario resignado y acorralado, vencido con todas las de la ley, envuelto en trapos y con la cara ensombrecida por la furia y la derrota, en una imagen crística de la vida que sigue a la muerte. Sus verdugos le dieron rostro, cuerpo y alma al mito que recorrería el mundo. (La vida en rojo 21 )

Y, al mismo tiempo, desde una mirada retroactiva a su vida, le permite enfatizar el encuentro entre un hombre y su época desde la dimensión cultural, pero recalcando la inviabilidad de sus ideas políticas. La biografía escrita por Pierre Kalfon es, por su parte, la más literaria de todas en su estilo. Ubicando al mismo tiempo al Ché en su contexto histórico -el entusiasmo de los movimientos de liberación en el Tercer Mundo y los movimientos ideológico-políticos que asumían la violencia como partera de la Historia, por ejemplo-, alude permanentemente a su afinidad con la 
indignación de Zolá, con la locura del Quijote, con el sufrimiento asmático de Proust, y también, implícitamente, con la consigna de Rimbaud: "transformar la vida".

Cuatro miradas, cuatro Chés distintos. Según Anderson, desde una mirada muy cercana a los intereses y la perspectiva cubana, un combatiente revolucionario, imbuido por un sentido de responsabilidad ante los males de la sociedad y por una voluntad misionera que lo llevó a acercarse a Marx desde muy joven. Héroe movido por la voluntad de desafiar al imperialismo ubicándose para ello él mismo en el campo de batalla. Marxista convencido de obedecer a un imperativo histórico, dispuesto a sacrificar su yo personal en aras de la revolución. Héroe social convencido de la posibilidad de un Hombre Nuevo, inquebrantable en sus convicciones, intachable en sus principios, congruente en sus acciones y pensamientos, aunque dotado también de "debilidades intrínsecas: la soberbia y la ingenuidad" (Anderson 703). Por otra parte, el Che Guevara que emana del voluminoso libro de Taibo II es no solo el santo laico de toda una generación de jóvenes latinoamericanos de izquierda, sino que, al mismo tiempo, un hombre de acción y a la vez un personaje irreverente, burlón y sarcástico, iconoclasta, provocador, antiburocrático y antijerárquico, vagabundo, aventurero o romántico (sin desconocer sus pésimos hábitos higiénicos o su concepción ingenua de la política en relación con la Unión Soviética). ${ }^{9}$ A su vez, en una biografía que pone el acento en lo político y lo cultural, planteando la consonancia de Guevara con su época (el voluntarismo de una generación que instauró el presente como imperativo de vida o la negación a vivir en la ambivalencia), el Che de La vida en rojo de Jorge Castañeda presenta a una figura nómade, errante e idealista, en movimiento permanente, motivado por el desasosiego, el amor al viaje y la aventura, fascinado por la Otredad, enamorado de su propia muerte, en perpetua "huida hacia adelante" en "busca de su tragedia" (70), impulsado a la muerte pero con un sentido providencial de la vida, un radical voluntarista, un rebelde que se enfrenta con el

9 Al narrar la adolescencia del Guevara en Córdoba, y entretejiendo su propia voz con la del Che, escribe Paco Ignacio Taibo: "Prosigue en el rugby con los hermanos Granado. Su amigo Barral lo recuerda como "el más duro". Sigue jugando con el vaporizador a un lado de la cancha. De aquella época es el apodo maldito que lucirá con orgullo.

- Me decían el Chancho.

-i Por lo gordo?

-No, por lo cochino.

Sus fobias al agua fría, que le desencadena a veces los ataques de asma, se han convertido en unos hábitos higiénicos poco sólidos. Su falta de amor por los baños y las duchas lo acompañará el resto de los días de su vida". (Taibo 27) 
sistema dominante más allá de lo político y que vivió la revolución en el desenfreno de la aventura, un hombre ajeno a la militancia partidista pero fascinado por la turbulencia de la guerra revolucionaria, que prefiere la aventura a la militancia, y el idealismo moral al pragmatismo de la política, por lo cual no podrá conciliar "los imperativos de sobrevivencia de la revolución cubana con las épicas y notables aspiraciones humanistas y sociales que le quiso imprimir" (42). Finalmente, la mirada -indulgente- de Pierre Kalfon presenta al Che como un rebelde, un humanista, un poeta, un romántico que prefería la idea poética al crudo realismo del poder, "más camusiano que sartreano" (611), en el sentido de dejarse matar por una idea, embarcado en una lucha imposible ajena al "arte de lo posible" que es la política. Para Kalfon, el Che era un personaje heroico de profunda exigencia ética, de espíritu espartano, un hombre de moral y exigencia ética, un radical intransigente pero también un ingenuo que defendía el imperativo de promover valores altruistas, un ferviente defensor de valores morales en una sociedad dominada por el capitalismo, ansioso por pasar a la acción con una inquebrantable fe en la revolución, dotado de una capacidad de sacrificio sobrehumana pero que termina siendo derrotado por la prosaica realidad, absolutamente consciente de que su misión tendría un final fatal. Pero sobre todo, según Kalfon, fue un portador de sueños y utopías, y de ahí su permanencia en el corazón de millones y millones de seres humanos hasta el día de hoy.

Si quien escribe una biografía es un artesano que dedica años de su vida a ponerse en los zapatos del sujeto que estudia, obsesionado por encontrar el rayo de luz que le permita descifrar alguna huella, algún rasgo esencial de una vida, trabajando a la manera de un detective que persigue a un criminal (el cual, en el género biográfico, es el biografiado), siempre a la caza de algún rastro que le permita armar un poco mejor el puzzle y resolver el enigma de una vida, cada uno de los biógrafos mencionados resulta ser un detective exitoso, aportando nuevos y desconocidos datos hasta ese momento. Así, por ejemplo, Anderson descubre la fecha verdadera de nacimiento del Che (14 de mayo y no 14 de junio de 1928) y, en el proceso de su investigación, entrevista al militar que comandaba la patrulla que lo capturó y que había formado parte del pelotón que lo enterró, quien le da los datos sobre la sepultura del Che en Vallegrande, mismos que permitieron que se desenterrara el cadáver y fuera llevado a Cuba. A su vez, Pierre Kalfon entrevista al asesino material del Che, Mario Terán. Jorge Castañeda, por su parte, 
presenta el testimonio del funcionario de la CIA, Fernando Rodríguez, un cubano exiliado, la última persona que habló largamente con el Che antes de su muerte; y Taibo II documenta, en un libro previo (1994) a través de entrevistas con compañeros del Che en su lucha guerrillera en el Congo y de la recepción del manuscrito del Che, Pasajes de la guerra revolucionaria (inédito hasta entonces y mantenido oculto por las autoridades cubanas), una de las etapas más desconocidas de la vida de Guevara: su experiencia durante 1965, organizando y apoyando a la guerrilla congolesa opuesta al gobierno de Moise Tshombe, quien había asesinado al dirigente Patricio Lumumba, primer presidente del Congo después de la descolonización. (Véase nota de pie 2).

Divergentes son también las miradas hacia puntos cruciales de la vida de Ernesto Guevara. Por ejemplo, entre muchos otros, ¿en qué momento y por cuáles razones se convierte en revolucionario? Para Anderson, es en Guatemala, entre 1954 y 1955, donde vivió el derrocamiento del Gobierno democrático de Jacobo Arbenz..$^{10}$ Habría sido allí y en ese momento cuando la indignación social lo acercó al marxismo y lo convirtió en un "un revolucionario auténtico". Pierre Kalfon coincide con esta hipótesis. En cambio, para Taibo II, en esa época era todavía esencialmente un vagabundo, un aventurero de fin de semana que soñaba con viajar a Europa. Castañeda, a su vez, conjetura que a pesar de su indignación por la injusticia social que primaba en América Latina en esa época, y del golpe de Estado contra Arbenz, Guevara era en esos años "un individuo que muestra una insaciable curiosidad política, aunada a una carencia persistente de espíritu militante; con opiniones políticas de izquierda desprovistas sin embargo de una formación marxista" (105).

Otro punto de divergencia se refiere a las razones por las cuales Guevara abandona Cuba en 1965. ¿Por diferencias teóricas y prácticas con el comunismo soviético y con el gobierno de Fidel Castro -como afirman Kalfon y Castañeda- o porque el fracaso de la guerrilla alentada por él en Argentina lo impulsó “a demostrar la efectividad de sus ideas" (Anderson 559), poniéndose él mismo al frente del combate, o porque se veía a sí mismo como un guerrillero - no un hombre de Estado- y consideraba que

10 Jacobo Arbenz llegó a la Presidencia de Guatemala en 1951, apoyado por obreros, campesinos, estudiantes e intelectuales. Su gobierno implementó políticas para expropiar los terrenos e intereses de la United Fruit Company y otras compañías norteamericanas. Acosado por la CIA como "filocomunista", a comienzos de 1954 asumió poderes especiales sospechando de un golpe de Estado en su contra, y a mediados de ese año una invasión de exiliados apoyados por Estados Unidos llevó a su dimisión y a la formación de una junta militar que declaró ilegal al Partido Comunista. 
su papel en América Latina era extender la experiencia revolucionaria cubana, tanto como un acto de vocación solidaria latinoamericanista como también por la voluntad irrefrenable de regresar a las hazañas heroicas impregnadas de olor a pólvora, como señala Taibo II? Más aún ¿Por qué incursionar precisamente en Bolivia, si ese país carecía de condiciones objetivas para un movimiento guerrillero? ¿Fue una decisión del propio Che para organizar desde allí un proceso revolucionario de largo plazo que llegara hasta Argentina, como afirma Anderson, o fue alentado por Fidel Castro, como conjetura Castañeda, con la promesa del apoyo del Partico Comunista Boliviano, que más tarde lo abandonó a su suerte ante la imposibilidad de la realpolitik de lidiar con un personaje tan incómodo como él?

Quizá de pocos personajes históricos se disponga de tantas fuentes para la escritura de su biografía, examinadas con lupa para aproximarse a la especificidad de su vida por nuestros cuatro biógrafos, como en el caso del Che. Pero ninguna biografía puede armar todas las piezas del rompecabezas, y son muchos los silencios que también forman parte del puzzle de su vida. ¿Cómo descifrar entonces la(s) ausencia(s) de algún fragmento de la vida de un hombre si no es a través de la imaginación? En el caso de Ernesto Guevara hay silencios oscuros y lagunas de información que las biografías -fieles al dato confirmable- no cubren, salvo de manera muy superficial y en pocas páginas: la referida a los meses entre marzo y julio de 1966, período que transcurre entre la derrota en el Congo y el inicio de la aventura final en Bolivia, tiempo que Guevara pasó en Praga clandestinamente. Es cierto que las lagunas de información acerca de estos cinco meses de la vida del Che Guevara se explican sobre todo por el secretismo con el que se llevó a cabo la operación. Pero ante tal vacío de evidencias confirmables, aparece la literatura, que ofrece a la actividad biográfica cierta libertad imaginativa y bastante más libertad conjetural, llenando los vacíos -y los misterios- dejados por la historia. En esta línea, el escritor argentino Abel Posse, en su libro Los cuadernos de Praga (1998), convierte al Che en un personaje novelesco, lejano a las narrativas biográficas que rondan la vida pública de Guevara pero que no abordan sus circunstancias más personales. En sus palabras: “Comprendí que las biografías, tan exactas y cuidadas... dejaban intacto lo central de Guevara, su intimidad" (10). Y agrega:

Comprendí que la mejor biografía, pegada al dato exterior y confirmable, es siempre como un esquema del biografiado, su 
yo de superficie, su gesticulación histórica: Me decidí a escribir desde una frase de Mijail Bajtin: "La novela es el triunfo de la vida sobre la ideología". Las biografías confirman al Guevara de las ideologías. Sólo la novela podía liberarlo de su imagen de profeta de la liberación. (11)

Además señala: "El género biográfico es más propio de la épica y de la consagración que del viaje hacia la intimidad del personaje” (189). Los Cuadernos de Praga constituyen un difuminado entretejido entre realidad y ficción literaria. Sustentado en las biografías de Anderson, Taibo II, Catañeda y Kalfon, y retomando de éstas los rasgos que cada uno atribuye al Che -el quijotismo (Kalfon), la fascinación por la muerte (Castañeda), el espíritu aventurero (Taibo II) y el heroísmo (Anderson)-, y en (¿supuestas?) entrevistas a guardaespaldas del Che en Praga, Posse recrea los supuestos Cuadernos de Praga, que se presume Guevara habría escrito en su escondite praguense pero cuya existencia no está confirmada. El propio Abel Posse cita a Pierre Kalfon (1997):

Corre el rumor de que durante aquel período de indecisión el Che vertió en algunos cuadernos sus reflexiones, vacilaciones y proyectos. Cosa imposible de comprobar, dado el hermetismo oficial de Cuba para con los escritos del Che. Si existen, esos hipotéticos Cuadernos de Praga deben de estar más guardados aún que ningún otro documento. Cuando se conoce la libertad de palabra de Guevara, cabe suponer que podrían ser dinamita. El interés de sus Cuadernos, siempre que aparezcan algún día, sería el de informarnos del estado de ánimo del condottiero mientras descansaba, durante aquellas largas jornadas de absurdo ocio, en una Praga soberbia y gélida. (507)

A partir de una supuesta versión mecanografiada de los Apuntes Filosóficos y los Cuadernos de Praga escritos por el Che, y que le habrían sido entregados a Posse por un colaborador de la policía secreta de la rama checa de la KGB -aunque la información existente señala que el gobierno checo no conocía la presencia de Guevara en Praga-, el escritor se introduce imaginariamente en lo que habría vivido y sentido un Guevara clandestino, que se repone de las dolencias físicas y anímicas del fracaso en el Congo, y que planea, al mismo tiempo, la expedición a Bolivia para extender, desde allí, la batalla definitiva de la revolución en Latinoamérica que gatillara la gran confrontación con el imperialismo. En un complejo juego narrativo, en la que se entretejen en diálogo las 
"burguesas" identidades imaginarias de Guevara con la voz del propio Che -quijotesca, provocadora, redentora-, así como los testimonios y el relato en primera persona del autor, Posse fractura la distinción entre un Che histórico y otro literario, acentuando precisamente lo que las biografías omiten. ¿Qué pensaba o sentía el Che en su obligado escondite en la triste ciudad socialista de Praga? ¿Qué leía? ¿Qué sentía al ver reflejado en el espejo cada mañana no al héroe guerrillero de la Sierra Maestra ni al diplomático que viajaba por el mundo defendiendo la revolución cubana, sino al aburrido burgués Raúl Vázquez Rojas, a Adolfo Mena, a Ramón Benítez - nombres falsos para ocultar su identidad-, a un sujeto disfrazado con lentes, una prótesis bucal y aburridos trajes grises? ¿Cuáles eran sus sueños, sus frustraciones, sus dudas? ¿Cuál es el balance que realizaba de su vida y de su convivencia con el asma? ¿Dialogaba con la muerte? Si la biografía como género está en la intersección entre historia y literatura, el libro de Posse reconstruye, en el cruce entre realidad e imaginación, el contradictorio mundo privado del Ché, sus posibles sentimientos, emociones, puntos de vista, maneras de sentir y estados de ánimo. Como toda biografía, es una interpretación en la que se condensa un trozo de vida, construida a través de fragmentos incompletos que intentan evocar el significado de una existencia o intuir rendijas que permitan entrever las dimensiones calladas u ocultas de la figura biografiada. Pero, en el cruce difuso entre realidad e imaginación, fiel a los datos históricos pero novelescamente a contrapelo de una escritura cronológica y ordenada, el Che literario de Abel Posse es el reverso del héroe mítico. Devorado por el desconsuelo, la soledad, la depresión, y la melancolía en la Praga socialista y triste, escapa a la vigilancia de sus guardaespaldas, deambula disfrazado de "burgués" por las callejas de la ciudad -aunque según Kalfon, a partir de testimonios de su guardaespaldas, salía poco de su escondite clandestino-, pasa largas horas en cafés para anotar sus reflexiones, escribe cartas entrañables, principalmente a su madre y a Fidel Castro, teje conspiraciones, activa su propia red de espionaje y convoca a sus compañeros más leales para preparar el viaje definitivo a Bolivia, aferrado a la "poética revolucionaria" (95) más allá del derrumbe total del modelo socialista que le expresan reiteradamente sus jóvenes amigos checos. "Un socialismo sin colores, de gente enojada. El socialismo del miedo, del orden aterrorizado" (135). Finalmente, con su fe indemne en la revolución, Guevara parte en tren hacia Viena rumbo a Cuba, desde donde iniciará la travesía final a Bolivia: 
Pachungo Montes de Oca, quien sabía que estaba ligado a su admirado jefe y que lo acompañaría hasta el final (murió el mismo día que él, en La Higuera, desangrándose de su herida en combate) se preguntó: ¿Quiere morir? ¿Quiere vivir? ¿Quiere triunfar o ser derrotado? ¿Quiere imponer su poder sobre la realidad o ser vencido por la torpe realidad de su tiempo para asumir el supremo y diamantino poder de transformarse en símbolo de todas las rebeldías justicieras de su tiempo? Pacho Montes de Oca pensó que buscaba tal vez la muerte de la transfiguración. Ese hombre con el chambergo gris, en el asiento 22 del tren a Viena, era el que intentaba lo extremo: el asalto al imposible. (306)

A cincuenta años de la muerte de Ernesto Che Guevara, Cuba, América Latina y la geopolítica mundial se han transformado de manera radical. La utopía del socialismo cubano se encuentra profundamente erosionada; la normalización de relaciones con Estados Unidos, el paulatino proceso de apertura al mercado y la muerte de Fidel Castro en 2016 marcarán, aun en medio de la incertidumbre actual, un futuro distinto para la isla. En América Latina, la muerte de Ché fue el punto de inflexión para la derrota de los movimientos guerrilleros y el surgimiento de dictaduras posteriores en países como Chile, Uruguay, Argentina y Brasil. Desde la década de los ochenta, los regímenes democráticos se han extendido en toda la región -sin dejar de reconocer su fragilidad, como lo evidencian las más recientes mediciones del Latinobarómetro-, e incluso, la última guerrilla que quedaba, las FARC -desprovista ya de toda ideología revolucionaria-, ha firmado la paz con el gobierno colombiano. En el ámbito internacional, la globalización y la revolución científico-tecnológica se han expandido planetariamente modificando, entre otros aspectos, las dimensiones de tiempo y espacio al tiempo que el mercado fagocita el sueño de la revolución. Y sin embargo, Ernesto Guevara, el Ché, -un personaje que escapa a toda definición, objeto de contradicción y polémica- sigue estando presente en nuevas biografías y novelas ( $O^{\prime}$ Donnell, 2003; Glasman, 2008; Muller, 2014). A pesar de las décadas transcurridas, quedan por explorar muchos materiales inéditos en torno a él. El archivo completo de sus notas, cuadernos, diarios, cartas y discursos está resguardado en Cuba, en el Centro de Estudios Che Guevara, y asimismo, numerosos archivos oficiales permanecen cerrados hasta el día de hoy, por ser considerados “material confidencial”. Su biografía está, todavía, inacabada. Y la gran novela sobre él sigue aún pendiente. 


\section{Referencias bibliográficas}

Anderson, Jon Lee. Che Guevara: una vida revolucionaria. Barcelona, Emecé, 1997.

Bazant, Milada. Biografía. Métodos, metodologías y enfoques. Coord. Milada Bazant. México, El Colegio Mexiquense, 2013.

Bustos, Ciro. El Che quiere verte: la historia jamás contada del Che en Bolivia. Buenos Aires, J. Vergara, 2007.

Caeiro, Alberto. Poemas inconjuntos, Madrid, Visor, 1984.

Castañeda, Jorge. La utopía desarmada. Barcelona, Ariel, 1995.

_. La vida en rojo. Una biografía del Che Guevara. México, Alfaguara, 1997.

Castilla, Amelia y Fietta Jarque. "Vivir las vidas ajenas”. El País. 29 de agosto 2009 , pp. 5-7.

Casullo, Nicolás, París 68. Las escrituras, el recuerdo y el olvido. Buenos Aires, Manantial, 1998.

Glasman, Gabriel. Breve historia del Che Guevara. Madrid, Nowtilus, 2008.

Huyssen, Andreas. En busca del futuro perdido. Cultura y memoria en tiempos de globalización. México, FCE, 2002.

Kalfon, Pierre. Che, Ernesto Guevara: una leyenda de nuestro siglo. Barcelona, Plaza y Janés, 1997.

Muller, Alberto. Che Guevara. Valgo más vivo que muerto. Madrid, Biblioteca Nueva, 2014.

O’Donnell, Pacho. Che. la vida por un mundo mejor. México, Plaza y Janés, 2003.

Posse, Abel. Los cuadernos de Praga. Buenos Aires, Atlántida, 1998.

Rico, Maite y Bernard De La Grange. “Operación Ché. Historia de una mentira de Estado". Letras Libres. Febrero 2007, Número 98, pp. 14-22.

Taibo II, Paco Ignacio. El año en que estuvimos en ninguna parte. La aventura guerrillera en el Congo, Buenos Aires, Ediciones Colihue, 1994.

_. Ernesto Guevara, también conocido como el Che. México, Planeta, 1996.

_. Ernesto Guevara, también conocido como el Che. México, Planeta, 2017.

Terán, Óscar. Nuestros años sesenta. Buenos Aires, El cielo por asalto, 1993. 